\title{
Out-of-district attenders: the passing trade of an accident and emergency department
}

\author{
G. M. BRYCE \& J. D. HOUGHTON
}

Department of Accident \& Emergency Medicine, Musgrove Park Hospital, Taunton, Somerset and Department of Anaesthetics, Royal Gwent Hospital, Newport, Gwent

\section{SUMMARY}

The resources of accident and emergency (A\&E) departments are often required to treat patients who are not within the catchment population of the local health authority. An assessment of workload caused by this particular group was carried out over a 2-month period at Northampton General Hospital which serves $\Phi_{\mathbb{D}}$ population of 318000 . Details were collected and analysed on the patients' reaso 8 for attendance, investigations and treatment.

\section{INTRODUCTION}

With the increasing mobility of the population, it is inevitable that many people will become ill or injured while away from home. A percentage of these will be treated as temporary residents by GPs but it was the impression of the authors that the majority of this load falls on the A\&E departments which may or may not be appropriate. In an attempt to assess the magnitude of this problem a study was carried out of all out-of-area attenders over a 2-month period between April and May 1991.

\section{METHODS}

The relevant case notes were reviewed and analysed by two members of the medical staff; age and sex details were recorded and day of the week was noted to establish whether or not the problems were greater at weekends. Place of

Correspondence: Miss G. M. Bryce, Consultant in Accident \& Emergency, Musgrove Park Hospital, Taunton, TA1 5DA, U.K. 
residence was also recorded. The reason for the patient's presence in the area was noted, being divided into those on business or study and those in the area primarily for the purposes of recreation. Further sub-division was made of patients passing through the area to a destination elswhere.

The severity of the patient's problem was assessed from the recorded notes and divided into six main groups. Admissions and deaths on arrival are selfexplanatory. The group with minor problems consisted of illnesses or injuries which were not deemed to necessitate medical advice, e.g. mild upper respiratory tract infections, superficial grazing which required only cleansing and soft tissue injuries not requiring $X$-rays. Moderate problems required further investigation and treatment, either with support bandaging, steristrips or drug therapy.

Significant problems consisted of fractures or wounds requiring suturing and patients requiring further follow-up. An assessment was also made as to whether or not the patient would have been more appropriately treated by a GP. This included patients with mild gastroenteritis, influenza, colds, skin rashes and injuries of over 1 month's duration.

\section{RESULTS}

During the study period a total of 529 patients who were resident outside the designated catchment area attended A\&E. This was $5.7 \%$ of the total number of new attenders in that period and, on this basis, would result in 3231 patients per annum. The age and sex characteristics of these patients are shown in Table 1. Of the total, $275(52 \%)$ were seen during weekdays and $254(48 \%)$ at weekends and Bank Holidays. As the latter obviously constitutes a smaller number of days it becomes a relatively greater proportion of the workload.

Fifty-two (10\%) patients resided in the adjacent areas and a further $123(23 \%)$ within the Oxford Region. The majority, 348 (66\%), were U.K. residents from further afield and only six (1\%) were visitors from abroad.

The patient's reasons for being in the area were recorded (Table 2). The majority, $305(58 \%)$, were visiting the area for recreational purposes either travelling through

Table 1. Age and sex distribution of patients studied

\begin{tabular}{cccr}
\hline Age range & Male & Female & Total \\
\hline $0-9$ & 34 & 27 & 61 \\
$10-19$ & 57 & 28 & 85 \\
$20-29$ & 108 & 39 & 147 \\
$30-39$ & 53 & 16 & 69 \\
$40-49$ & 48 & 14 & 62 \\
$50-59$ & 23 & 13 & 36 \\
$60-69$ & 17 & 17 & 34 \\
$70-79$ & 11 & 16 & 27 \\
$>80$ & 3 & 5 & 8 \\
Total & $354(67 \%)$ & $175(33 \%)$ & 529 \\
\hline
\end{tabular}


Table 2. Reason for presence in area

\begin{tabular}{lr}
\hline $\begin{array}{l}\text { Work, study or business } \\
\text { Passing through for purposes } \\
\text { of work, study or business }\end{array}$ & 114 \\
& 27 \\
Visiting relatives or friends & 69 \\
Holiday & 121 \\
Sport & 47 \\
Other recreational pursuits & 31 \\
Passing through for purposes & \\
of recreation & 37 \\
& \\
Residing at home & 43 \\
Irregular discharges & 35 \\
Travelling families & 5 \\
\hline
\end{tabular}

the area or visiting the town or its environs as an end point. Only $141(26 \%)$ were here for reasons of study, work or travelling through on business. A total of 430 (8\%) patients chose to travel to Northampton General from home rather than attend their designated hospital, the reasons for this were various, in some cases ${ }_{\infty}^{\infty}$ the distance was less and in others it was preference, arising from prior experience. $\frac{\vec{\Phi}}{\mathbb{Q}}$ There is no reason to suppose that there is not a similar flux in the opposite 3 direction. A small number of patients $(5[1 \%])$ were from nomadic travelling families. A total of $35(6.7 \%)$ patients did not wait to be seen by the examinigges doctor. Where recorded, the longest waiting time was $2 \mathrm{~h}$; details on these patientsse were limited to the information gathered by receptionists and basic nursing triageg notes.

The reasons for attendance are listed in Table 3. The larger number of sportso injuries in Table 3 than in Table 2 is explained by the fact that many people play

Table 3. Aetiology

\begin{tabular}{lc}
\hline Trauma & \\
Work accident & 75 \\
Sports injury & 81 \\
Road traffic accident & 67 \\
Home accident & 51 \\
Assault & 20 \\
Accident in street & 17 \\
Total & $311(58 \%)$ \\
Non-Trauma & \\
Medical & 91 \\
Surgical & 44 \\
Orthopaedic & 27 \\
Dental & 7 \\
Psychiatric & 4 \\
ENT & 13 \\
Gynaecology & 3 \\
Ophthalmic & 1 \\
Other/Not known & 28 \\
Total & $218(41 \%)$ \\
\hline
\end{tabular}


informal games while on holiday and while visiting recreation parks. These are additional to those sustained in formal organized games where players have come to the area purely to participate in a specific sport.

Investigations included 188 requests for $\mathrm{X}$-rays, 18 for ECG and 62 requests for tests from the medical laboratories. A total of $59 \%$ of the patients required no investigation other than a history and examination. It is interesting to note that the percentage of patients who were in the study group and who required X-rays was $35 \%$, which is similar to the overall figure for all new attenders, of whom $32 \%$ were X-rayed.

Details of investigations and treatments are shown in Tables 4 and 5. In both cases the total numbers exceed the sample number as individual patients may have had more than one form of investigation or treatment.

In the various categories of severity (Table 6), 164 (31\%) patients were considered to have minor problems, $239(46 \%)$ were moderately severe and $64(12 \%)$ were considered to have a significant problem. A total of $60(11 \%)$ of the patients were admitted and two patients were pronounced dead on arrival.

One hundred and one (17\%) patients could have been seen by a GP and 401

Table 4. Investigations

\begin{tabular}{lr}
\hline X-rays & 188 \\
Biochemistry & 28 \\
Haematology & 23 \\
ECG & 18 \\
Microbacteriology & 11 \\
None & 313 \\
Patient Refusal & 1 \\
\hline
\end{tabular}

Table 5. Treatments

\begin{tabular}{lr}
\hline Pharmacy & 132 \\
Support & 90 \\
Dressing & 78 \\
Sutures & 42 \\
Plaster cast & 22 \\
Tetanus prophylaxis & 17 \\
Minor operation & 13 \\
Manipulation & 5 \\
No specific treatment & 201 \\
\hline
\end{tabular}

Table 6. Severity of complaint

\begin{tabular}{lr}
\hline Minor & 164 \\
Moderate & 239 \\
Significant & 64 \\
Total admission & 60 \\
Deaths & 2 \\
\hline
\end{tabular}


(76\%) were appropriate A\&E attenders. The remaining patients, $(35 ; 4 \%)$, eithe did not wait or ought to have attended some other agency - most often a dentist $\frac{}{\mathbb{N}}$

\section{DISCUSSION}

This A\&E Department sees between seven and ten patients per day who are nof resident in the designated catchment area.

The significant number of patients, $164(31 \%)$, attending with minor problems may reflect the fact that when away from home, people do not have the same support from family and friends or access to simple analgesics, dressings and advice from their own GPs as when in their usual surroundings.

The authors believe that $101(19 \%)$ of the attenders could have been treated adequately by a GP. Indeed some people had tried to do so, but when they weré unable to get an immediate appointment, the A\&E department was their nex source of aid, particularly when they were due to travel on or move within $24 \mathrm{~h}$ g The majority, 401 (76\%), were considered appropriate attenders and must be accepted as a group which requires advice, treatment and care from the staff ando resources of an A\&E department.

Recent changes in the methods of financing health care in the U.K. have concen $\frac{3}{3}$ trated on local purchaser-provider arrangements dependent on the patient's place of residence. To date, emergency care has been provided as an essential servee and cross boundary charges only initiated if patients were admitted. There is z్ possibility that, with the increasing number and autonomy of trust units, compense may be sought for patients whose care does not require admission This would apply, particularly to areas with a small resident population but a large⿳⺈冂𠃍. daily or seasonal influx of people. In many places this would constitute a mucho greater proportion of the A\&E workload than in the case of Northampton. The authors have been unable to find references to any published work giving infor 3 mation on this subject. The administration work of recovering such costs woulde be significant and often difficult. The patient's designated provider may be un: willing to pay if they viewed the attendance unnecessary. It is important that funding for this group is allocated centrally.

Table 7. Discharges

\begin{tabular}{lr}
\hline Home with no follow-up & 349 \\
Referred to GP & 47 \\
Admitted & 55 \\
Referred to local hospital & 28 \\
Return to A\&E or fracture clinic & 17 \\
Referred to Eyes or ENT & 11 \\
Irregular discharge - did not wait & 16 \\
Transferred to another hospital & 4 \\
(psychiatric \& plastics) & \\
Died & 2 \\
\hline
\end{tabular}

